\title{
Proficiency of fundamental motor skills in children of a public school in the city of São Paulo
}

\author{
DÉCIO RODRIGUES ${ }^{1}$ | ERIC LEAL AVIGOำ | JOSÉ ANGELO BARELA1,2
}

${ }^{1}$ Cruzeiro do Sul University - Institute of Physical Activity and Sport Sciences | ${ }^{2}$ State University of São Paulo - Institute of Bioscience

Correspondence to: José Angelo Barela, Cruzeiro do Sul University, Institute of Science and Physical Education, Galvão Bueno Street, 868, Floor 13, Block B - Liberdade, 01506-000 São Paulo, SP, Brazil

Email: jose.barela@cruzeirodosul.edu.br

\begin{abstract}
AT A GLANCE
Nine-year-old children showed fundamental motor skill proficiency superior than 6-year-old children; The Brazilian children tested, ages 6and 9-year-old, showed delayed fundamental motor skill proficiency compared to the TGMD2 normative data for these age groups; Fundamental motor skill proficiency delay was greater in the older age group;
\end{abstract}

\section{ACKNOWLEDGEMENTS}

We are thankful to CAPES (Coordenação Aperfeiçoamento de Pessoal de Nível Superior) and $\mathrm{CNPq}$ (Conselho Nacional de Desenvolvimento Científico e Tecnológico) for financial support.

\begin{abstract}
BACKGROUND: Studies have indicated that Brazilian children are failing to meet expected proficiency, regarding the chronological age, in performing gross motor skills.

AIM: The aim was to verify the proficiency of fundamental motor skills of 6- and 9-year-old children from a public school in the city of São Paulo.

METHOD: Eighty-two children were selected from the first and fourth Elementary School year, 40 children from the first (6.6 year-old, 20 boys and 20 girls) and 42 children from the fourth year ( 9.2 year-old, 21 boys and 21 girls). Children were videotaped performing the Test of Gross Motor Development, locomotor and object-control subtests. Three experimenters inspected the video images and rated the children's performance following the suggested criteria.

RESULTS: Nine-year-old children were advanced in fundamental motor skill proficiency compared to 6-year-olds, but children from both age groups were delayed to the expected fundamental motor skill proficiency. Moreover, the proficiency delay was even more pronounced in the older age group, with 6-year-old rated as poor whereas 9-year-old children rated as very poor in fundamental motor skill development.

CONCLUSION: These results raise several concerns regarding the importance of mastering the basic motor skills and future enrollment in motor activities.
\end{abstract}

\section{INTRODUCTION}

A critical aspect for participation in an activity, in any domain, certainly is proficiency in such activity. In the motor domain this is not different, and motor proficiency is important for a physically active lifestyle. Studies have indicated that motor development proficiency and physical activity participation are related throughout infancy and adolescence, 1,2 and adulthood 3, 4. While skillful adolescents and young adults become more involved in physical activities and sports 1-3, those who have not mastered fundamental motor skills during infancy tend to become less involved in physical activities and less physically active ${ }^{1,5}$.

Despite being crucial, becoming proficient in motor skills is not trivial and requires practice and repetition to achieve a proficient pattern ${ }^{6}$. Moreover, considering that motor development is a lifespan continuous and cumulative process ${ }^{7-10}$, motor proficiency requires full development in all periods in such way that previous experiences become the basis for experiences and development in the subsequent periods. Therefore, motor proficiency is a result of a long developmental process that requires active participation in adequate activities regarding the participant's developmental level. Although demanding, 
such efforts are rewarded not only by making the involvement in sport activities possible but also by allowing the individual to become skillful throughout the lifespan in which the acquired motor repertoire is critical in allowing proper motor actions in the daily activities ${ }^{11}$.

On the other hand, lack of motor proficiency may become a barrier in the continuous developmental process with consequences as self- and/or peer-exclusion of activities as recently discussed 7,10 . Our everyday activities are good examples of this issue. In which activities do we engage: in those in which we most likely will fail or in those in which we most likely will succeed? Who will most likely be preferred as a teammate? The individual who is skilled or not skilled? Therefore, our motor engagement choices are based on our mastered skills.

Although lack of motor proficiency is prejudicial in any developmental period, Seefeldt e Haubenstricker ${ }^{12}$ were the pioneers in suggesting that unskillfulness might be more detrimental when it occurs in the fundamental motor skills. Fundamental motor skills are basic and necessary for any motor action throughout life and are considered as building blocks for specialized and more elaborated skills such as sport skills ${ }^{6-8,13}$. In this case, if fundamental motor skills are not mastered, children might show difficulties in acquiring and performing more elaborate skills and, as a consequence, facing a motor proficiency barrier $7,8,12$. Therefore, mastering the fundamental motor skills is a necessity in order to grant full motor development, allowing children, adolescents, adults, and older adults to be most likely physically active throughout the lifespan and motivated to engage in physical activities, taking advantage of health benefits in a enjoyable way 6, 14 .

Therefore, assessment of motor competence should be implemented to ensure monitoring of the developmental process of children, especially in the first decade of life. One of the tools available to infer the level of development of children during the first decade of life and thus to identify, for example, delays in proficiency of fundamental motor skills is the Test of Gross Motor Development, second edition (TGMD-2) ${ }^{15}$. Although TGMD-2 provides standardized norms for American children, which might lead to questions of its application to other populations, it has been widely used to investigate different purposes and in different cultural populations ${ }^{16-22}$.

Several studies have demonstrated that structured and systematized activities combined with proper instruction and information regarding the performance of a motor skill, provided by a specialized professional, in the case the physical education teacher, promote improvement of the fundamental motor skill performance of Brazilian children ${ }^{16}$, 20,23 . However, one common observation is that the Brazilian children are failing to achieve the expected proficiency, regarding chronological age, in performing gross motor skills ${ }^{24-26}$. Despite these results, until the present moment, researchers have yet to examine the proficiency of the fundamental motor skills in Brazilian school children. Therefore, the purpose of this study was to examine the proficiency of the fundamental motor skills of 6and 9-year-old children from a public school in the city of São Paulo.

\section{METHODS}

\section{Participants}

Eighty-two children, regularly enrolled in a public school in the suburbs of the city of São Paulo, participated in this study. These children were randomly selected from first and fourth grades. Specifically, the sample consisted of 40 children (20 boys and 20 girls) 
from the first grade (mean age of 6.6 years), and 42 children (21 boys and 21 girls) from the fourth grade (mean age of 9.2 years). Each child's parent was informed about the purpose of the study and gave written permission by signing a consent form approved by the Ethical Committee of Cruzeiro do Sul University. The children provided assent to participate.

\section{Procedures}

Data collection took place at the school gym. Initially, birth date, hand and foot preference, weight, and height were obtained. Following, children were videotaped performing the locomotor and object-control skill subtests of the TGMD-2 ${ }^{15}$.

In order to do so, a digital camera (Sony Model DCR-HC96) was positioned in a half of the court in such way that it was possible to videotape the participants, in the sagittal plane, performing the run, gallop, hop, leap, horizontal jump, and slide tasks. Another digital camera (Sony Model DCR-HC96) was positioned in the other half of the court allowing videotaping the participants' sagittal plane performing the striking a stationary ball, stationary dribble, catch, kick, overhand throw, and underhand roll tasks. The cameras' arrangement was based upon previous studies ${ }^{16,20,23}$ and the children's identity was preserved with them being identified by numerical information previously defined.

Children were instructed according to the TGMD-2 guide and each skill was demonstrated by the instructor ${ }^{15}$ and then the child performed 3 trials of each motor skill. The first trial, as suggested ${ }^{15}$, was performed in order to make sure that the child had understood what was required and the following two trials were considered for further analysis. If the child had not understood the task, additional information and/or demonstration were provided and the child performed the task again.

Videotaping of each subtest took about 7 minutes, with the total time necessary to assess each child taking about 15 minutes. Children performed first the locomotor followed by the object-control subtest. Information and demonstration were provided by the same previously trained instructors, for both locomotor and object-control tasks.

\section{Data Analysis}

After data collection, videotaping was edited in such way that two valid trials were identified and separated for further analysis. Each task performance was evaluated by three experimenters, previously trained, assessing the performance criteria according to the test instructions ${ }^{15}$. In this way, when the child's performance fulfilled the performance criterion, a score of 1 was attributed and when the performance did not fulfilled the performance criterion, a score of zero was attributed. A concordance agreement was computed among the evaluators, dividing the number of agreement by the sum of agreements and disagreements ${ }^{27}$, with the minimum acceptance agreement no less than 0.85 .

The sum of the values assigned to the performance criteria for both trials performed by the child was computed, for each subtest, locomotor and object control. This total for each subtest abilities, following the TGMD-2 instructions ${ }^{15}$, was considered the raw scores for the locomotor and object control subtests separately. The maximum total possible, for each subtest, was 48 points and the closer to this total value the better is the child's performance, according to the performance criteria. 
Based on the total raw score, motor age equivalent was obtained, indicating the approximate age that the child's performance corresponds. Motor age equivalent was obtained for each child in both locomotor and object control subtest, following the normative data of the TGMD-2 ${ }^{15}$. Furthermore, the gross motor quotient was obtained, which is a composite of the results of both locomotor and object control subtests. The gross motor quotient value, according to Ulrich ${ }^{15}$, is the most important value derived from the TGMD-2, because it is based on the locomotor and object control skills' performance and represents the best estimative of the child's gross motor proficiency. Based upon the obtained motor quotient value, it is also possible to descriptively rate the child motor development as very poor, poor, below average, average, above average, superior, and very superior ${ }^{15}$.

\section{Statistical Analysis}

Since data met normality (Shapiro-Wilk test) and homogeneity of variance (Levene test) assumptions, a multivariate analysis of variance (MANOVA) was employed to compare anthropometric measures between the groups (6- and 9-year-old children), having as dependent variables age, weight, height and body mass index. Other two MANOVAs were used in order to test possible differences between groups regarding the locomotor and object-control performance. In this case, one MANOVA had as dependent variables the raw scores and the equivalent motor age for the locomotor subtest. Another MANOVA had as dependent variables the raw scores and the equivalent motor age for the object-control subtest. In addition, the equivalent motor age, for each subtest, was compared to the respective group chronological age. In order to so, one-sample t tests were used to compare the locomotor and object-control equivalent motor age to the chronological age for children in each age group.

When necessary, univariate analyses were performed and the significance level was kept at 0.05. All analyses were run using the SPSS (SPSS version 17).

\section{RESULTS}

Table 1 depicts anthropometric information of the 6- and 9-year old children. MANOVA revealed differences between groups, Wilks' Lambda $=0.013, F(4,77)=1448.89$, $p<0.001$. Univariate analyses indicated that children 9-year-old were older, $F(1,80)=5617.52, p<0.001$, heavier, $F(1,80)=22.89, p<0.001$, and taller, $F(1,80)=116.61$, $p<0.001$, than children 6 -year-old. However, univariate analysis did not reveal any group difference for the $B M I, F(1,80)=0.2, p>0.05$.

Table 1: Mean (standard deviation) of chronological age, weight, height, body mass index (BMI), and locomotor and object control equivalent motor age for the 6- and 9-year-old children.

\begin{tabular}{ccccccc}
\hline Groups & $\begin{array}{c}\text { Chronological Age } \\
\text { (years) }\end{array}$ & Body Mass $(\mathrm{kg})$ & Height $(\mathrm{m})$ & BMl $\left(\mathrm{kg} / \mathrm{cm}^{2}\right)$ & $\begin{array}{c}\text { Locomotor } \\
\text { Equivalent Age }\end{array}$ & $\begin{array}{c}\text { Object Control } \\
\text { Equivalent Age }\end{array}$ \\
\hline 6-year-old & $6.63(0.17)$ & $24.1(5.2)$ & $1.18(0.5)$ & $17.1(2.4)$ & $4.78(0.64)$ & $4.88(1.23)$ \\
9-year-old & $9.25(0.14)$ & $31.0(7.6)$ & $1.33(0.6)$ & $17.2(3.0)$ & $5.22(0.59)$ & $6.38(1.00)$ \\
\hline
\end{tabular}


Regarding the TGMD-2, all children were able to perform the tasks of both subtests. Figure 1 depicts the raw scores and equivalent motor age from the locomotor and object-control subtests of 6- and 9-year-old children. For the raw score values, MANOVA revealed group effect, Wilks' Lambda=0.692, $F(2,79)=17.61, \quad p<0.001$. Univariate analyses indicated that differences occurred for both locomotor, $F(1,80)=8,70$, $p<0,005$, and object control, $F(1,80)=33,56, p<0,001$. In both cases, raw scores were higher for 9 - than for 6 -year-old children. For the equivalent motor age, MANOVA revealed group effect, Wilks' Lambda $=0.670, F(2,79)=19.44, p<0.001$. Univariate analyses indicated that differences occurred for both locomotor, $F(1,80)=10.15, p<0.005$, and object control, $F(1,80)=36.43, p<0,001$. In both cases, equivalent motor ages were higher for 9 - than for 6 -year-old-children.

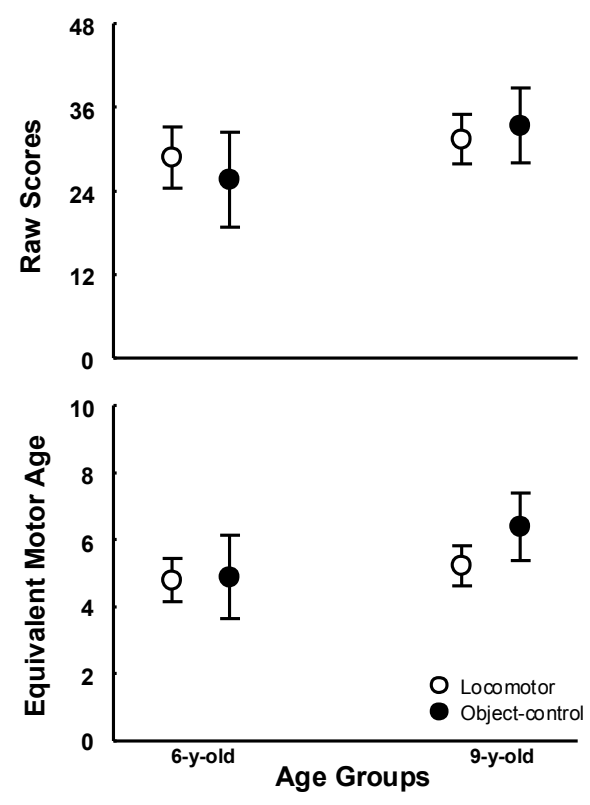

Figure 1. Mean and standard deviation of raw scores (top) and equivalent motor age (bottom) for locomotor and object control subtests of 6 - and 9-year-old children.

T tests revealed that equivalent motor age is bellow chronological age for the 6year-old children regarding the locomotor, $t(39)=-18.00, p<0.001$, and object-control, $\mathrm{t}(39)=-8.93, p<0.001$, subtests. Similarly, $t$ tests revealed that the equivalent motor age is bellow the chronological age for the 9-year-old children for both locomotor, $t(41)=-44.03$, $p<0.001$, and object-control, $t(41)=-18.51, p<0.001$, subtests (Table 1).

The difference observed between the chronological and the equivalent motor ages is different for 6 - and 9-year-old children. MANOVA revealed that the this difference is significantly larger for the 9-compared to the 6-year-old children, Wilks' Lambda $=0.262$, $F(2,79)=111.03, p<0.001$, for both locomotor, $F(1,80)=224.87, p<0.001$, and object-control, $F(1,80)=19.70, p<0.001$, indicating that the equivalent motor age does not follow in the same rate the increment in the chronological age. Such developmental delay difference between groups is depicted in the descriptive rating. Table 2 depicts gross motor quotient values for 6- and 9-year-old children. As it can be observed, 6-year-old children were classified as poor whereas 9 -year-old children were classified as very poor. 
Table 2: Mean (standard deviation) of gross motor quotient and the respective descriptive rating of 6- and 9year-old children

\begin{tabular}{ccc}
\hline Groups & $\begin{array}{c}\text { Gross Motor } \\
\text { Quotient }\end{array}$ & Descriptive Rating \\
\hline 6-year-old & $77.5(9.6)$ & Poor \\
9-year-old & $69.1(7.6)$ & Very Poor \\
\hline
\end{tabular}

\section{DISCUSSION}

The goal of this study was to examine the proficiency of fundamental motor skills of 6- and 9-year-old children from a public school of São Paulo city. The results showed that older children present a better development compared to younger children, but both children groups are falling behind the expected proficiency level considering the respective chronological age. Moreover, the developmental level of the fundamental motors skills of the observed children in both age groups of this study, 6- and 9-year-old, were rated as poor and very poor, suggesting that motor development delay increases as the chronological age increases. Finally, the factors related to this lacking of expected development and the implications of such developmental level are discussed.

The results from this study show that the TGMD-2 can discriminate fundamental motor skill performance of children with different age, even in a small Brazilian children sample. Our results showed that proficiency in performing gross motor skills is different between 6- and 9-year-old children examined in the TGMD-2. Despite discriminating proficiency of fundamental motor skill in children of different ages, which is not surprising, our results clearly indicated the children that participated in this study do not show the proficiency of fundamental motor skills according to their respective chronological age. Although such observation must be cautiously taken because the TGMD-2 normative data are based on American children sample, our results indicate that children from the examined school exhibit lower equivalent motor age compared to the American children's standards. Such results corroborate several other study results $20,23,28$ in which was observed that Brazilian children are lagging behind in mastering the fundamental motor skills.

We have showed that different contexts ${ }^{16}$ and even intervention ${ }^{20}$ at schools and in short program interventions ${ }^{26}$ can promote changes in the performance of fundamental motor skills. Therefore, we can suggest that a possible aspect impacting gross motor skill proficiency observed in this study might be due to the lack of appropriate intervention and/or contexts that would promote improvement of these motor skills.

Another important issue demonstrated by our results is that the proficiency delay in performing both locomotor and object-control skills is larger at older children age. Motor development is a cumulative long process $7,8,10$ in which previous experiences are used as founding blocks for subsequent acquisitions and proficiency. Although we have not longitudinally followed our children, the difference in chronological and equivalent motor age is intriguing. The detrimental aspect regarding the developmental level of our children, 
in the present study, rated as "poor" and "very poor", at ages of 6- and 9-year-old, respectively, is that such level of development might prevent them to participate in many activities. As suggested by Barela ${ }^{10}$, proficiency is a key aspect and even mandatory in allowing one to be involved in motor activities such as recreational and daily leisure. Thus, competent mover, more likely will be more involved in activities ${ }^{23}$. Unfortunately, we may infer that the opposite condition is also applicable in such way that less competent mover tend to be less involved is such activities ${ }^{1}$.

Finally, our results raise an important issue related to the improvement of the fundamental gross motor skills even in early ages. We have already showed that regular physical education in the first elementary schools years ${ }^{16}$ and even in the kindergarten 20 improves fundamental motor skill proficiency. Considering that our results show that Brazilian children lagged behind the TGMD-2 normative data, we can wonder if such difference could be minimized due to early intervention either in specific programs or in Physical Education activities. However, as previously suggested such activities must be directed to provide structured practiced, based upon children's expected developmental level, followed by appropriate information targeting improvement in motor competence, as recently discussed ${ }^{10}$. Although physical education goals must go further and beyond the acquisition of fundamental motor skill competence, this is a critical step that must be also pursued. Despite the fact that physical education at school for many seems to only focus on the practice, if this were the case the results have been quite disappointing. Our children have failed to even acquire the basic skills, which will be required for more complex activities. Failing to do so, our children might be exposed to an unfair condition that prevent them to be enrolled in many situations related to our movement context.

The present study presents a few limitations. First, children participating in this study came from only one school what might have biased our results, although our results are in agreement with previous results. We have been working in order to uncover this issue with a much larger sample from a representative school distribution, covering different ages and sex as well. Second, we have not controlled the frequency and quality of the physical education and other non-formal activities that children possibly were enrolled. Actually, such lack of control of possible diversity of influences that could have influenced motor development was proposal since the goal was to examine the level of fundamental motor skill development of children in general.

\section{CONCLUSION}

Older children showed better development of fundamental motor skills compared to young children, but both 6- and 9-year-old children are delayed in their fundamental motor skill proficiency compared to the expected development. Moreover, the observed developmental delay was greater for the 9-year old children. Based upon the expected development, 6-year-old children were rated as poor whereas 9-year-old children were rated as very poor. These results might be interpreted as an important indicator that our children might be prevented to further enrollment of physical activities due to lack of fundamental gross motor skill proficiency.

\begin{tabular}{l|l|l|l}
\hline $\begin{array}{l}\text { Rodrigues, Avigo \& } \\
\text { Barela }\end{array}$ & 2015 & VOL. 9 & N.1 \\
\hline
\end{tabular}




\section{REFERENCES}

1. Fisher A, Reilly JJ, Kelly LA, et al. Fundamental movement skills and habitual physical activity in young children. Medicine and Science in Sports and Exercise. 2005;37(4):684-8.

2. Ridgway $\mathrm{CL}$, Ong KK, Tammelin TH, Sharp S, Ekelund U, Jarvelin MR. Infant motor development predicts sports participation at age 14 years: Northern Finland birth cohort of 1966. PLOS ONE. 2009;4(8):e6837.

3. Okely AD, Booth ML, Patterson JW. Relationship of physical activity to fundamental movement skills among adolescents. Medicine and Science in Sports and Exercise. 2001;33(11):1899-904.

4. Stodden D, Langendorfer S, Roberton MA. The association between motor skill competence and physical fitness in young adults. Research Quarterly for Exercise and Sport. 2009;80(2):223-9.

5. Wrotniak BH, Epstein LH, Dorn JM, Jones KE, Kondilis VA. The relationship between motor proficiency and physical activity in children. Pediatrics. 2006;118(6):e1758-65.

6. Pelegrini AM, Barela JA. O que o professor deve saber sobre o desenvolvimento motor de seus alunos. In: Micotti MCDO, ed. Alfabetização: assunto para pais e mestres. Rio Claro: Divisa, 1998:69-80.

7. Clark JE. On the problem of motor skill development. JOPERD. 2007;78(5):39-45.

8. Gallahue DL, Donnelly FC. Educação física desenvolvimentista para todas as crianças. São Paulo: Phorte, 2008.

9. Haywood K, Getchell N. Desenvolvimento motor ao longo da vida. Porto Alegre: Artmed, 2004.

10. Barela JA. Fundamental motor skill proficiency is necessary for children's motor activity inclusion. Motriz. 2013;19(3):548-51.

11. Lopes L, Lopes VP, Pereira B. Atividade física no recreio escolar: estudo de intervenção em crianças dos seis aos 12 anos. Revista Brasileira de Educação Física e Esporte. 2006;20(4):271-80.

12. Seefeldt $V$, Haubenstricker J. Patterns, phase, or stages: an analytical model for the study of developmental movement. In: Kelso JAS, Clark JE, eds. The Development of Movement Control and Coordination. New York: John Wiley \& Sons Ltd, 1982:309-18.

13. Gabbard CP. Lifelong Motor Development. San Francisco, CA: Brown \& Benchmark Publishers, 1996.

14. Clark JE. Motor development. Encyclopedia of Human Behavior. 1994;3:245-55.

15. Ulrich DA. Test of gross motor development - 2. Austin, TX: PRO-ED, 2000.

16. Cotrim JR, Lemos AG, Júnior JEN, Barela JA. Desenvolvimento de habilidades motoras fundamentais em crianças em diferentes contextos escolares. Revista da Educação Física/UEM. 2011;22(4):523-33.

17. Hardy LL, King L, Farrell L, Macniven R, Howlett S. Fundamental movement skills among Australian preschool children. Elsevier Science Publishers BV. 2009(13):503-8. 
18. Houwen S, Hartman E, Jonker L, Visscher C. Reliability and validity of the TGMD-2 in primary-school-age children with visual impairments. Adapted Physical Activity Quarterly. 2010;27(2):143-59.

19. Kordi R, Nourian R, Ghayour M, Kordi M, Younesian A. Development and evaluation of a basic physical and sports activity program for preschool children in nursery schools in iran: an interventional study. Iranian Journal of Pediatrics. 2012;22(3):357-63.

20. Lemos AG, Avigo EL, Barela JA. Physical education in kindergarten promotes fundamental motor skill development. Advances in Physical Education. 2012;2(1):17-21.

21. Pang AWY, Fong DTP. Fundamental motor skill proficiency of Hong Kong children aged 69 years. Research in Sports Medicine. 2009;17:125-44.

22. Valentini NC, Rudisill M. Motivacional climate, motor-skill development, and perceived competence: two studies of developmentally delayed kindergarten children. Journal of Teaching in Physical Education. 2004;23:216-34.

23. Rodrigues D, Avigo EL, Leite MMV, Bussolin RA, Barela JA. Desenvolvimento motor e crescimento somático de crianças com diferentes contextos no ensino infantil. Motriz. 2013;19(3):S49-56.

24. Ferraz OL. Desenvolvimento do padrão fundamental de movimento correr em crianças: um estudo semi-longitudinal. Revista Paulista de Educação Física. 1992;6(1):26-34.

25. Valentini NC. Percepções de competência e desenvolvimento motor de meninos e meninas: um estudo transversal. Movimento. 2002;8(2):51-62.

26. Braga RK, Krebs RJ, Valentini NC, Tkac CM. A influência de um programa de intervenção motora no desempenho das habilidades locomotoras de crianças com idade entre 6 e 7 anos. Revista da Educação Física/UEM. 2009;20(2):171-81.

27. Thomas JR, Nelson JK. Métodos de pesquisa em atividade física. Porto Alegre, RS: Artmed, 2002.

28. Brauner LM, Valentini NC. Análise do desempenho motor de crianças participantes de um programa de atividades físicas. Revista da Educação Física/UEM. 2009;20(2):205-16.

Citation: Rodrigues D, Avigo EL, Barela JA Proficiency of fundamental motor skills in children of a public school in the city of São Paulo A. BJMB. 2015: 9(1): 1-10.

Editor: Joao A. C. Barros, California State University Fullerton, Fullerton, CA, USA.

Copyright: @ 2015 Rodrigues D NonCommercial-NoDerivatives, Avigo EL, Barela and BJMB. This is an open-access article distributed under the terms of the Creative Commons Attribution- 4.0 International License which permits unrestricted use, distribution, and reproduction in any medium, provided the original author and source are credited. Competing interests: The authors have declared that no competing interests exist.

Download: http://socibracom.com/bjmb/index.php/bjmb/issue/view/24 